\title{
Apóstoles del proletariado andaluz. Panorama de la edición libertaria en Andalucía (1903-1936)
}

\author{
Alejandro Civantos Urrutia \\ Universidad de Granada
}

Título: Apóstoles del proletariado andaluz. Panorama de la edición libertaria en Andalucía (1903-1936).

Resumen: La preeminencia que tuvo el anarquismo como movimiento social en Andalucía durante más de cincuenta ańos, hasta la Guerra Civil, ha sido abordada por numerosos especialistas, aunque por lo general no se ha considerado de manera suficiente la importancia de su proyecto educativo y cultural. En el presente trabajo se analiza el alcance y las dimensiones del entramado editorial libertario en Andalucía como clave para la construcción de una alternativa cultural propia, específicamente obrera, que alejara al proletariado de la tutela burguesa, como paso previo y necesario para la revolución.

Palabras clave: Anarquismo, Cultura, Educación, Editoriales, Andalucía.

Fecha de recepción: 14/3/2020.

Fecha de aceptación: 24/4/2020.
Title: Andalusian Proletariat Apostles. Outlook of the Anarchist Publishing in Andalusia (19031936).

Abstract: The significance of Anarchism as social movement in Andalusia for over 50 years up to the Spanish Civil War has been studied by many specialists. However, the importance of its educational and cultural program has not been sufficiently addressed. This paper analyses the scope and dimensions of the framework of publishers in Andalusia linked to the libertarian movement as key to build a solid —explicitly working classcultural alternative able to break free from bourgeois' control, seen as a necessary previous step towards the revolution.

Key words: Anarchism, Culture, Education, Publishers, Andalusia.

Date of Receipt: 14/3/2020.

Date of Approval: 24/4/2020.

\section{Raíz libertaria de Andalucía}

Pese a la importancia histórica que tuvo el anarquismo en España en los cincuenta ańos que precedieron a la Guerra Civil, no son muchos los estudios que hayan analizado con cierto detalle la magnitud y alcance de su proyecto cultural. Y menos aún en Andalucía, cuya singularidad 
en el conjunto del anarquismo español había sido subrayada de manera temprana por el notario de Bujalance y futuro diputado republicano Juan Díaz del Moral en su justamente célebre Historia de las agitaciones campesinas andaluzas (1929). Desde entonces, la extraordinaria fortaleza del anarquismo en el sur de España ha tenido numerosos exégetas que, obviando la cuestión cultural, se han aproximado al fenómeno desde muy diversas perspectivas, a menudo excluyentes cuando no impregnadas de la beligerancia propia de la época que pretendían estudiar.

El mismo Díaz del Moral abonó la tesis de un cierto milenarismo, primitivo e irracional, al referirse a los anarquistas como "secta" de "bienaventurados jerarcas de la candidez", incultos y entusiastas jornaleros, subsumidos en la espera del Gran Día, en el que "la fortaleza capitalista se hundiría sin más esfuerzos, como los muros de Jericó al

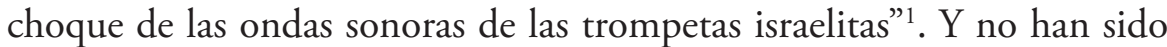
pocos los que, en su estela, han presentado el anarquismo andaluz, más que como una acción política, como poco menos que una epifanía, pues "el comportamiento y las estructuras mentales de los libertarios parecían provenir de una época ya pasada y de una cultura diferente: la de los primeros tiempos de la predicación cristiana" 2 .

Para Malefakis, describir el impacto del anarquismo en el sur de España con analogías religiosas (los “apóstoles de la idea”, el "nuevo evangelio", la "predicación") estaba, de hecho, bastante justificado ${ }^{3}$, pues de lo que en verdad se trataba era de una reacción contra el industrialismo y un intento de retorno a las tradiciones agrarias comunales de la primera y muy espiritual Edad Media. En esa línea, se encontrarían Gerald Brenan, que caracterizaba al anarquismo casi como una herejía cristiana cuyo anticlericalismo no era sino "la rabia de un pueblo intensamente religioso que se siente abandonado o decepcionado" ${ }^{4}$, o Eric Hobsbawn, que apuntaba el milenarismo de los libertarios andaluces como razón de su

1 Juan Díaz del Moral, Historia de las agitaciones campesinas andaluzas, Madrid, Alianza, [1929] 1973, p. 201.

2 Gilles Lapouge y J. Bécaraud, Los anarquistas españoles, Barcelona, Editorial Laía, 1969, pp. 144-145.

3 E. Malefakis, Reforma agraria y revolución campesina en la España del siglo XX, Barcelona, Ariel, 1982, pp. 168-169.

4 Gerald Brenan, El laberinto español, Barcelona, Backlist, [1962] 2008, p. 265. 
ineficacia como revolucionarios, pues "esperan que [la revolución] se haga ella sola, por revelación divina, por una proclamación que venga de arriba, por un milagro" ", algo que, a juicio del historiador inglés, contrasta con la modernidad de otros movimientos sociales, como el marxismo, más organizados pero con menos predicamento en Andalucía.

Todas estas tesis sobre el irracionalismo ácrata y su mesiánico primitivismo tienen por lo general el inconveniente de ser aproximaciones más bien ahistóricas, tendentes a atribuir el éxito del anarquismo en Andalucía a rasgos casi de carácter, pues, como sugiere Corbin, intentan de algún modo establecer "una correlación explícita o implícita entre el «atraso» del anarquismo y el «atraso» de la comunidad andaluza: aislada, inadecuada, rural, arcaica, primitiva" ${ }^{6}$. Insisten, además, en un componente casi exclusivamente rural y agrario del anarquismo andaluz que hace tiempo quedó ya desestimado ${ }^{7}$.

Otros historiadores, como Tuñón de Lara en varios trabajos, han intentado contextualizar el arraigo del anarquismo en nuestro país como consecuencia de la deficiente configuración de la burguesía española, que tendió a asimilarse a la aristocracia y a los terratenientes en lugar de combatirlos, dejando al movimiento obrero carente de la referencia reformista que estaba encabezando las revoluciones europeas ${ }^{8}$. Así, habrían sido las fallidas propuestas sociales de la burguesía liberal y su escaso compromiso con las necesidades reales de la clase trabajadora las que habrían hecho decantarse al obrero por movimientos sindicales apenas formalizados, suspicaces con la política, ajenos al sistema de

5 Eric Hobsbawn, Rebeldes primitivos, Barcelona, Ariel, 1983, p. 96.

6 John Corbin, "El anarquismo andaluz: perspectiva desde la antropología social", Revista de Antropología Social, 2 (1993), pp. 73-104 (pp. 74 y 80).

7 En efecto, el 66,2\% de los anarquistas españoles eran andaluces, pero de estos solo el 50,8 \% serían campesinos, según datos del Congreso de la FTRE en Sevilla de 1882: Antonio M. Calero, Movimientos sociales en Andalucía (1820-1936), Madrid, Siglo XXI, [1976] 1987, pp. 25-26.

8 Vid. "Sociedad señorial, revolución burguesa y sociedad capitalista 1834-1860", en Manuel Tuñón de Lara, Estudios de Historia Contemporánea, Barcelona, Hogar del Libro, 1982, pp. 93-110; o "La burguesía y la formación del bloque de poder oligárquico: 1875-1912”, en Manuel Tuñón de Lara, Estudios sobre el s. XIX español, Madrid, S. XXI editores, 1973, pp. 155-238, además de su monumental El movimiento obrero en la Historia de España, Madrid-Barcelona, Taurus/Laia, [1972] 1977, III vols. 
representación y capaces de darle una respuesta más agresiva frente al poder. Y ello sobre todo en Andalucía, donde el fracaso de la reforma agraria fue mayor, pues la desamortización de bienes de manos muertas no hizo sino aumentar las concentraciones de tierras haciendo aún más dependientes de los caciques a los trabajadores del campo, y más extremas, por tanto, las condiciones de explotación de los latifundios.

De hecho, "la experiencia negativa de la República Federal parece que marcó definitivamente al campesinado de la baja Andalucía y lo inclinó para siempre por el radicalismo anarquista" ${ }^{\circ}$. Al respecto, el mítico líder cantonal gaditano Fermín Salvochea llegó a afirmar: "después de lo ocurrido en el 73, creo que nada debe esperarse ya de la política" ${ }^{10}$. Ese desencuentro con la política iría además unido en el sur de España a la escasez de tejido industrial y, sobre todo, a la pervivencia del latifundio, cuya importancia como entidad jurídica y casi espiritual de Andalucía ha sido estudiada asimismo con profundidad ${ }^{11}$. Todo esto habría llevado al proletariado andaluz a sentirse más concernido por La conquista del pan de Kropotkin que por El Capital de Marx, pues ninguna otra doctrina social entendió mejor el problema de la tierra que el anarquismo. No se trataba, por tanto, de espontaneísmo insurreccional ni de primitivismo mesiánico, sino de una acción de clase dirigida "contra las relaciones mismas de producción capitalista en el campo"12. O, dicho de otra manera, el anarquismo andaluz "fue menos un movimiento primitivo que una respuesta moderna a determinadas situaciones primitivas" 13 .

9 Antonio Ma Calero, "El movimiento obrero en Andalucía", en Aproximación a la historia de Andalucía, ed. Juan Antonio Lacomba, Barcelona, Laia, 1979, pp. 279298 (p. 285).

10 Apud Jacques Maurice, El anarquismo andaluz. Campesinos y sindicalistas. 18681936, Barcelona, Crítica, 1990, p. 159.

11 Vid. especialmente los trabajos Miguel Artola et al., El latifundio. Propiedad y explotación ss. XVIII y XX, Madrid, Ministerio de Agricultura, Servicio de Publicaciones Agrarias, 1978; Antonio Miguel Bernal, "Latifundios, jornaleros y paro agrícola", Revista de Estudios Andaluces no 8 (1987), pp. 67-86; y Edward Malefakis, op. cit.

12 Ramón Rodríguez, "El proletariado agrícola andaluz como clase social", Estudis d'Historia Agraria, 2 (1979), pp. 171-192 (p. 171).

13 José Luis Gutiérrez Molina, “Andalucía y el anarquismo (1868-1936)”, Ayer, 45, 1 (2002), pp. 171-196 (p. 184). 
No obstante, quedaría por aclarar la importante presencia urbana o no exclusivamente agraria del anarquismo en Andalucía, así como que el otro gran foco de irradiación peninsular fuera la Cataluña industrial, aunque autores como Maurín o Balcells hayan dado respuesta aunque sea parcial a este asunto al considerar la emigración campesina andaluza a Cataluña como posible germen del anarquismo español ${ }^{14}$.

Por último, aproximaciones recientes han destacado la importancia que pudo tener en la expansión de la acracia el combate contra el analfabetismo. Es significativo que este no superara la media europea hasta el s. XVIII, y que fuera en el XIX, y especialmente desde la Restauración, cuando se incrementó hasta alcanzar los 12 millones de analfabetos entre una población de 18,6 en torno a 1900. En 1910, el analfabetismo afecta a un $59,79 \%$ de la población espańola; en el mundo rural, llegaba hasta el 82,56 \%. Todavía en 1926 el Ministerio de Instrucción Pública cifraba el analfabetismo en Andalucía en el 66,26 \%, casi el doble que en la Castilla la Vieja de entonces. Jaén, Málaga y Granada lideraban la tasa de analfabetismo en Espańa, por encima del 75 \%, y en algunas poblaciones se superaba el 90 \%, como es el caso de Santiago de la Espada, en el extremo norte de la provincia de Jaén, que, con su 92,8 \%, ostentaba el dudoso honor de tener la tasa de analfabetos más elevada de España. Ningún programa institucional parecía tener interés en subsanar el problema de la educación en las clases subalternas, y menos aún en Andalucía, donde daba la impresión incluso de que para la pervivencia del latifundio era necesaria la cruda ignorancia. En 1929, Luis Bello, intentando analizar para el diario El Sol "las causas del famoso 92.8\%" de Santiago de la Espada, afirmaba:

Yo he llegado a convencerme de que la gran propiedad no quiere escuelas. La Propiedad, ente de razón, podía comprender que elevándose el nivel de cultura suben todos los valores, incluso el de la tierra. Pero el propietario, el don Fulano, o el tío Fulano, de vida limitada, teme ser él, en su generación, víctima de cambio tan hondo. Y tan necesario. Prefiere que las cosas sigan como van. El pueblo,

14 Joaquín Maurín, Revolución y contrarrevolución en España, París, Ruedo Ibérico, 1966, p. 21; y Albert Balcells, El arraigo del anarquismo en Cataluña. Textos 19261932, Barcelona, A. Redondo, 1973, p. 91. 
abajo, con su ignorancia y su bienaventurada pobreza de espíritu. Instruirle es soliviantarle. Por eso tiene tanta fuerza aquella frase del secretario [del Ayuntamiento] de Pontones: "Aquí no necesitan saber escribir más que mi hijo y el hijo del señor Alcalde"15.

En 1895, antes incluso de haber visitado la "Andalucía Trágica”, el futuro Azorín ya decía en su serie de Anarquistas Literarios: "Defiéndase la instrucción. Haga la iniciativa particular lo que el Estado no hace: fúndense instituciones para la enseńanza, créense escuelas donde el obrero aprenda a ser hombre y hacer efectivos sus derechos" ${ }^{16}$.

$Y$, en efecto, a diferencia de otros movimientos sociales, los ácratas pusieron en el centro la cuestión educativa, y quizá sea este un aspecto que no debe ignorarse para calibrar su fuerte arraigo en el sur, pues para ellos no se trataba de un tema residual ni de una mera consecuencia del estado de cosas: el analfabetismo era la losa que impedía la emancipación como clase del proletariado. Por eso, la "misión cultural" del anarquismo era, de algún modo, parte de su estrategia revolucionaria, de ahí la proliferación de escuelas racionalistas, bibliotecas libertarias o proyectos editoriales que fueron dando cuerpo a una acción formativa amplia y diversificada, dentro de lo que hoy se llamaría "educación no formal". Puesto que desconfiaban de que la burguesía pudiera llevar a efecto ese proceso, desarrollaron sus propios procedimientos Así, puede "decirse sin exageración que para el anarquismo, más que para ninguna otra doctrina política, ha tenido la cultura un valor máximo no como impulsora de bienestar social sino como un logro político-social en sí misma"17. El proyecto cultural anarquista fue la primera escuela de muchos peones

15 Luis Bello, Viaje por las escuelas de Andalucía, Sevilla, Centro de Estudios Andaluces, [1929] 2007, p. 476. Para todo el desglose de cifras: Antonio Viñao "La alfabetización en España: un proceso cambiante en un mundo multiforme", en Perspectivas históricas en la educación de personas adultas, coords. Pedro Luis Moreno Martínez y Clotilde Navarro García, Salamanca, Universidad de Salamanca, 2009, III, pp. 5-29; y José A. Piqueras Arenas, "Educación popular y proceso revolucionario español", en Clases populares, cultura, educación. S. XIX y XX. Coloquio hispanofrancés, Madrid, UNED, 1989, pp. 77-96.

16 Azorín, Obras Completas, Madrid, Aguilar, 1958, I, p. 171.

17 José Álvarez Junco, La ideología politica del anarquismo español, Madrid, Siglo XXI, 1991, p. 73. 
de gañanía, braceros de latifundio o segadores de cereal. Sin ese germen pensaban que la revolución sería imposible, de ahí que tuviera carácter de apostolado, de viaje de largo alcance cuyo destino final era la construcción de un mundo nuevo.

\section{Coordenadas de la Jerusalén obrera}

Desde un punto de vista teórico, lo que llevó a tantos militantes libertarios a emprender proyectos editoriales fue la lucha contra el desconocimiento y la incultura en las que se hallaban las clases más desfavorecidas, así como, tal vez, el entusiasmo de hacerlo con medios propios, convencidos del abandono y aun la manipulación a la que se creían sometidos por una burguesía que, en palabras de Ricardo Mella, convertía a "simples hombres en hombres simples"18.

La editorial cordobesa Renovación Proletaria decía en su volumen inaugural:

Nuestro propósito no es otro que el de difundir entre los esclavos el espíritu de libertad, para engrandecer económica e intelectualmente la familia humana [...]. Nuestro interés propagar, por la cultura, ideas que hagan de la tupida y oscura manigua del pensamiento, cerebros por razonamiento equilibrados, base del Amor y de la Equidad social ${ }^{19}$.

La revista Acracia iba aún más allá y se presentaba así a sus lectores:

Pretendemos hacer conocer a los explotados todos del campo, del taller y de la mina, los derechos inmanentes a cada uno y cuya restricción absurda es consecuencia de nuestra miseria y nuestra ignorancia.

Vamos a hacer labor educativa y cultural, esparciendo por doquier las sabias doctrinas que han de perfeccionar al hombre pre-

18 Ricardo Mella, "La hipérbole intelectualista", Natura, 1 (1 de octubre de 1903), pp. 9-12 (p. 11).

19 Ángel Pestaña y Salvador Seguí, El sindicalismo en Cataluña, Pueblonuevo del Terrible (Córdoba), Renovación Proletaria, 1920, p. 1. 
sente para vivir armónica y fraternalmente en la sociedad futura [...] lejos de las tendencias paternalistas que con cinismo torpe mantienen políticos sin escrúpulos y sin conciencia.

“-Para ganar una batalla — decía Napoleón, el grande—, hacen falta tres cosas: dinero, dinero y dinero". Nosotros decimos: para ganar la batalla de las reivindicaciones proletarias hace falta CULTURA, CULTURA Y CULTURA ${ }^{20}$.

La primera fase de aquel proceso fue, sin duda, la prensa obrera. Los inicios de la prensa libertaria andaluza están ligados al frustrado intento de creación en 1882, en el II Congreso de la Federación de Trabajadores de la Región Española, de una Federación Regional Andaluza, diferenciada de la muy legalista y burocrática dirección nacional. A este convulso periodo del anarquismo andaluz corresponden cabeceras como La Solidaridad, La Alarma, La Autonomía o La Tribuna Libre, todas editadas en Sevilla; pero también El Trabajo de Málaga o El Obrero de Riotinto, editado en la población onubense, así como El Oprimido o El Trabajo, ambos de Cádiz, al igual que el importantísimo El Socialismo, cuyo director y redactor principal fue el legendario cantonalista y primer alcalde republicano de la ciudad Fermín Salvochea, quien, desde 1886 hasta 1891, de manera intermitente, pues "sale cuando puede", intentó hacerse eco de la prensa internacional y difundir las ideas anarco-colectivistas presentándose en sus últimos números como "quincenario comunista anarquista" 21.

En el cambio de siglo la avalancha de prensa libertaria era ya una realidad ineludible. Solo en Sevilla están documentadas las siguientes publicaciones: Justicia, Humanidad, El Trabajo, Los Tiempos Nuevos, Verdad, la Verdad de Andalucía, Unión de Trabajadores, El noticiero Obrero, Espartaco, Hoja del Pueblo, Acción Solidaria, Solidaridad Obrera, El Productor, La Anarquía y Páginas Libres. Además, en Aznalcóllar encontramos Los Nuestros; en Écija, Regeneración Obrera; en Herrera, Alma Agraria y en Morón de la Frontera, Juventud Rebelde. En Huelva se tiene constancia de La voz del Obrero y de un Internaciona Laboristo, editado en esperanto, además de los de localidades mineras como Nerva,

20 “De nosotros para todos ¿a qué venimos?", Acracia, 1 (12 de mayo de 1918), p. 1.

21 Vid. Miguel Íñiguez, Enciclopedia histórica del anarquismo español, Vitoria, Asociación Isaac Puente, 2008, II, pp. 1562-1563, y Jacques Maurice, op. cit., pp. 151-170. 
con El Ideal, o Calañas, donde se editaba El Obrero. Uno de los centros neurálgicos de la prensa ácrata fue, como ya se ha visto, Cádiz, donde podían leerse La Voz del Obrero del Mar, El Proletariado, Germinal, La Tribuna Obrera, Nuevo Espartaco, Rebelión o Tribuna Libre, además de La Voz del Esclavo y La Razón en Algeciras; Aurora y Prometeo en San Fernando y, en Puerto Real, El Obrero Moderno. En La Línea se editaban nada menos que La Protesta, El Despertar del Terruño, El Anticristo, El Precursor y Aurora. En Jerez, cuna de grandes terratenientes, se editaba La voz del campesino. Por su parte, en Jaén encontramos El Rebelde y El Reflector, ambos de Linares. En Córdoba, Alas, que se editaba en Castro del Río, Vía Libre en Peñarroya y Nuevo Rumbo en Pueblonuevo del Terrible. En Málaga, La Aurora del Siglo, Arte y Ciencia y Acción Obrera. En Almería salía Unión Ferroviaria. De Granada tenemos constancia de al menos dos: El Rebelde y Acción Obrera ${ }^{22}$.

Se trataba por lo general de una prensa "antisistema", centrada en temáticas obreras generalmente orilladas por la prensa tradicional y cuyos colaboradores eran lo que podía llamarse autores "sucios" o "impuros", con frecuencia "anti-intelectuales", peones de gañanía, labradores, segadores, a veces mineros o ferroviarios recién salidos del analfabetismo, escritores no profesionales que, no obstante, conectaron con las ansias de transformación social del proletariado andaluz mucho mejor de lo que lo hacían las cabeceras socialistas o republicanas. El propio Díaz del Moral lo expresaba de esta forma:

La prensa obrera está llena de artículos de campesinos cordobeses y no son pocos los folletos escritos por manos encallecidas por la azada [...]. Los periódicos anarquistas y sindicalistas necesitaban un redactor para leer, interpretar y escribir de nuevo los numerosos artículos de estos colaboradores espontáneos. El socialismo tendría aquí más adeptos si su prensa publicara también este tipo de artículos radicalmente enemigos de todo precepto gramatical ${ }^{23}$.

Esta explosión de prensa obrera que se dio en realidad en toda España fue, en puridad, la primera cartilla de lectura de muchos trabajadores,

22 Juan Díaz del Moral, op. cit., pp. 495-497.

23 Ibidem, pp. 217-218. 
víctimas de las desigualdades, la desidia y el analfabetismo, pero para ellos también se asentaba en el convencimiento algo intuitivo de que la cultura era un fenómeno de clase, y la que hasta entonces se había consumido como tal estaba corrompida y puesta al servicio de la clase dominante. El periódico La Nueva Idea, por ejemplo, tenía a gala afirmar en su número 1 de 1895 que "no hallarán en él las galanuras literarias y las flores de retórica que abundan en la prensa burguesa..., la prostituta que se vende a cualquiera por dinero", y aún más rotundamente el semanario Juventud definía en 1903 la prensa establecida como "la podrida, exposición magnífica del cretinismo intelectual de quien de su pluma hace herramienta de embrutecimiento y tiranía" 24 .

Como se observa, junto al carácter formativo había un claro espíritu militante, indisoluble para ellos del anterior y, en todo caso, una clara vocación de distinguirse de los productos culturales establecidos:

La literatura fue y es conceptuada como un artículo de lujo, y por eso el que lo expende lo adorna, lo dora y lo pinta. Para nosotros es muy distinto. La literatura es un medio de lucha, un reflejo de la revolución que está actuando el proletariado, y por eso toma tinte violento y tiene ímpetu de cargas a fondo. Escribimos para exponer una lucha violenta o desesperada, para protestar de un crimen, para denunciar una iniquidad, para revelar una felonía, etc., y estos temas obligan al lenguaje áspero, la argumentación fuerte. De ahí que la literatura sindicalista sea violenta ${ }^{25}$.

A juicio de los promotores de prensa libertaria, el combate contra el arte y la literatura como predominio exclusivo de las clases privilegiadas debiera ir en paralelo al esfuerzo por construir una cultura propia, alternativa y revolucionaria, reclamando otros niveles y modos de comunicación de fuerte base colectiva. Por eso se daba cabida en sus páginas a trabajadores del campo o de la mina, o se proponía como firmantes de los artículos a "un zapatero", "un viticultor" o "un jornalero" con el que espontáneamente pudieran identificarse los lectores.

24 Apud Lily Litvak, Musa libertaria, Madrid, Fundación de Estudios Libertarios Anselmo Lorenzo, 2001, p. 215.

25 Fulano de Tal, "La literatura heroica", Unión Ferroviaria (S.C.), III, 52 (16 junio 1914), p. 4. 
De ahí que, junto a la prensa obrera, se desarrollara todo un entramado de publicaciones en un intento por construir ese modelo editorial "distinto" al que aspiraban. Lo paradójico es que muchas de estas experiencias, inspiradas de manera ecléctica en el periódico, la revista ilustrada y las incipientes "ediciones populares", acabaron compartiendo modelo editorial con las colecciones de novela corta de quiosco que consolidó en 1907 "El Cuento Semanal”, fructífero híbrido de periodismo y literatura dirigido por Eduardo Zamacois, que editaba novelitas cortas en papel de lujo, de afamados escritores, ilustradas por dibujantes de mérito, y cuyo extraordinario éxito pobló la vida literaria española de numerosas publicaciones similares ${ }^{26}$. Las colecciones libertarias, por lo general de más tosco aspecto y con ausencia de ilustraciones, compartían con aquellas el carácter periódico y popular, de quiosco, con formato de revista o folleto, la impresión a dos columnas, ciertas innovaciones tipográficas, el bajo coste (que oscilaba entre los 30 céntimos de "El Cuento Semanal" y los 5 que llegó a costar "La Novela Corta”) y la brevedad casi urgente de sus contenidos; pero se diferenciaban de ellas en un marcado rechazo a "la aristocracia espiritual del libro" que aquellas reclamaban ${ }^{27}$, además de por el contenido político-formativo, la abundancia de disertaciones y ensayos, y la reivindicación de autores procedentes del mundo del trabajo manual.

Rechazaban asimismo el "obrerismo sentimental" de los folletines decimonónicos, de los que muchas colecciones de quiosco aún bebían, y que tanto había contribuido, a su juicio, a crear una "falsa conciencia" en el proletariado ${ }^{28}$. Por último, intentaban definirse por un cierto carácter

26 Carmen Urioste-Azcorra, Narrativa andaluza: 1900-1936, Sevilla, Universidad de Sevilla, 1997, pp. 28-29, llega a documentar más de 70 colecciones, desde las que compartían la idea de editar cierta literatura galante cercana a lo erótico hasta las abiertamente políticas como La Novela Roja (1922-23, con nueva salida en 1931), La Novela Proletaria (1932-1933) o la muy longeva La Novela Ideal (1925-1938) de la familia Montseny. Vid. también Gonzalo Santonja, La novela revolucionaria de quiosco, Madrid, El Museo Universal, 1993; y, sobre El Cuento Semanal, Manuel Martínez Arnaldos, "El cuento semanal: proyecto y preparación”, Monteagudo, $3^{\mathrm{a}}$ época, 12 (2007), pp. 11-26.

27 Vid. José-Carlos Mainer, Historia de la literatura española, 6. Modernidad y Nacionalismo (1900-1939), Madrid, Crítica, 2010, p. 187, y Manuel Martínez Arnaldos, op. cit., p. 17.

28 Juan Ignacio Ferreras, La novela por entregas. 1840-1900, Madrid, Taurus, 1972, p. 29. 
marginal que las distinguiera de las publicaciones prestigiosas o librescas. Muchas de ellas surgieron incluso en zonas agrarias o enclaves rurales totalmente desconectados de la vida editorial del momento. En cuanto a su labor, a menudo se trató, sencillamente, de colecciones de monografías, que solían denominarse bibliotecas, vinculadas a un periódico y a veces a una escuela; otras, de pequeńas imprentas o editoras, dedicadas en exclusiva a la difusión de textos, libertarios o no, que escaparan del mainstream cultural, afrontando nuevas temáticas o planteamientos desde una perspectiva proletaria. La mayor parte de estas experiencias fueron efímeras o de muy escaso catálogo, épica de muchas de estas aventuras editoriales; otras, en cambio, desarrollaron catálogos más amplios y se consolidaron como alternativas solventes al establishment editorial de su tiempo.

En buena medida, lo que editaban eran esencialmente folletos de 16 a 32 carillas de texto generalmente a dos columnas y a una sola tinta. El formato más habitual era de 17x12 centímetros, que utilizó, por ejemplo, la sevillana Biblioteca del Obrero, aunque también hubo formatos más amplios, de revista, o intermedios como el de 20x14 que eligió la cordobesa Renovación Proletaria. La mayoría de las veces carecían de cubiertas, que encarecían el producto al tenerse que utilizar nuevas planchas, y solo las más lujosas disponían sobre la primera página una frágil laminilla de papel cebolla o un medallón ovalado con retrato del autor, como ocurría en la última editorial mencionada. También se editaron productos más prosaicos como postales con temáticas sociales (La igualdad burguesa o Los mártires de Chicago) o retratos de "figuras eminentes" (Kropotkin, Bakunin, Ferrer i Guardia, Salvochea) con fragmentos de sus obras en el anverso. Incluso se publicaban los conocidos como Almanaques Libertarios, una suerte de misceláneas históricas, científicas y literarias que, bajo la apariencia de calendarios, funcionaban como eclécticas enciclopedias sobre los grandes hechos del mundo obrero. Podían alcanzar las 200 páginas. Todo ello fue esencial para impulsar nuevas formas de cultura popular emanadas del propio pueblo y acordes con las realidades históricas de su tiempo, y para convertir la lectura en aliciente esencial para unas capas de la sociedad hasta entonces excluidas de aquellos circuitos.

La política de precios de estas publicaciones fue otro de los ganchos con los que se conquistó al lector obrero, que difícilmente podía 
permitirse las 4 pesetas de media que costaba un volumen comercial. En cambio, el folleto anarquista rondaba los 20 céntimos y su precio fue además bastante estable durante casi cincuenta años. Por ejemplo, Entre campesinos de Errico Malatesta, publicado por primera vez en España en 1889 por una Agrupación de Propaganda Socialista de Sabadell, se distribuyó tempranamente en Andalucía y hasta tuvo edición propia por el grupo El Espejo de Málaga en 1895. Para 1920 era todo un éxito que superaba las 20 ediciones, incluyendo una en la Biblioteca Económica de Úbeda. Con sus más de 50 páginas, el volumen nunca superó los 20 céntimos, e incluso se hicieron ediciones benéficas o de distribución gratuita entre simpatizantes de los distintos ramos sindicales ${ }^{29}$.

Intentando regatear las limitaciones de la distribución convencional, las editoriales anarquistas promovieron también nuevos sistemas al efecto, y además de venderse en quioscos o a reembolso, mediante listas de distribución, utilizaron redes de "paqueteros", una especie de corresponsales sin ánimo de lucro, trabajadores o simpatizantes del sindicato, que recibían los paquetes en su casa y se encargaban de venderlos por los rincones más insospechados: gañanías y galpones, hazas, mercados de abastos o cortijadas; en definitiva: allí donde estuviesen los trabajadores a los que apelaban. Una editorial como Renovación Proletaria, por ejemplo, situada en Pueblonuevo del Terrible, minúsculo enclave rural en el Alto Guadiato cordobés, llegó a disponer de distribuidores de "paquetes" no solo en España sino también en Francia, Argentina, Brasil, Chile, Cuba, Méjico, Puerto Rico y Perú ${ }^{30}$.

A diferencia de las colecciones de novelas cortas de su tiempo, el contenido de los folletos libertarios rara vez fue la ficción. Hubo circunstancialmente poesía, alguna breve novela social o teatro, pero por lo general se trataba de ensayos divulgativos en los que se mezclaban sin pudor la lucha obrera, testimonios de la represión, el ateísmo, el antibelicismo, el libro práctico sobre primeros auxilios o tratamientos de fertilidad agrícola, pero también el vegetarianismo, el naturismo, el

29 Ignacio Soriano y Francisco Madrid, Antología Documental del anarquismo espanol, VI.I (2016), pp. 251-252: http://www.cedall.org/Documentacio/IHL/Antologia\%20Documental\%20del\%20Anarquismo\%20espanol_Bibliografia.pdf [consultado 24/02/2020].

30 Ibidem, pp. 19-31. 
feminismo, el control de la natalidad o el esperanto; en definitiva, un caudal de conocimientos realmente poco frecuentado entre nosotros y con el que pretendieron singularizar su oferta. Junto a ello fue muy frecuente la edición de textos educativos, que se empleaban a veces en las escuelas racionalistas. Es el caso de la mayor parte de los volúmenes de la sevillana Biblioteca del Obrero, cuyo catálogo incluía diálogos racionalistas para niños, breves textos de divulgación científica, folletos de etimología, de geografía básica o de formación sexual, además de compendios formativos para obreros que posteriormente fueron muy imitados por otras editoriales menos militantes.

Por último, resta consignar el papel del autor en esta revolución editorial subterránea que planteaba el anarquismo. Los autores de estos folletos procedían de cinturones industriales, focos mineros o, más aún, de oficios artesanos o de las labores más humildes del campo. Se trataba, en fin, de proponer una cultura a pie de calle, sacada del día a día de peones o mozos de taller y con la que los nuevos lectores proletarios pudieran identificarse de inmediato. En cierto sentido, se trataba de anti-intelectuales como Vicente Ballester, esmerado ebanista en Cádiz y autor de dramas sociales como La voz de la Sangre o Escoria Social; o del jornalero de Grazalema José Sánchez Rosa, autor de textos educativos para obreros; o de la planchadora cordobesa Rafaela Salazar, autora de títulos feministas como Sólo para mujeres o La mujer y el cura; o del minero Higinio Noja Ruiz, onubense de Nerva, con textos tan demoledores como Los sombrios, sobre la vida de los trabajadores de Riotinto. La lista sería nutrida y reveladora de una no pequeña porción de escritores que pudieron ser y no fueron.

\section{Vida y Milagros de los apóstoles de la cultura}

Es posible que la primera colección de folletos ácrata andaluza en el siglo XX fuera, en 1903, Biblioteca El Despertar del Terruño, impulsada en la Línea de la Concepción por el jornalero jerezano José Torralvo Bermejo, analfabeto hasta los veinte años. Vinculada al periódico obrero del mismo nombre fundado dos años antes, la colección, que sepamos, solo alcanzó a editar dos títulos, ambos de ese mismo año: Las Leyes, de Palmiro, probable seudónimo del propagandista gaditano Abelardo 
Saavedra, que no volvió a editarse, y La idea anarquista de José Sánchez Rosa, con prólogo del propio José Torralvo, que llegó a alcanzar cuatro ediciones en diferentes colecciones obreras. En ambos casos aparece como imprenta la de la Viuda de Araújo y se vendían a 10 céntimos. Por su parte, se sabe que Torralvo, que había participado en numerosas huelgas campesinas, emigró a Argentina tras la represión de 1909, a la zona de Rosario, donde siguió fundando periódicos y escuelas obreras e incluso llegó a hacer carrera regular como periodista hasta que murió en 1943. Fue autor de títulos como Sacrificio y heroísmo de España, sobre la Guerra Civil, y de la notable obra teórica La revolución. Estudio constructivo de la civilización del Trabajo ${ }^{31}$.

También bastante efímera fue la colección de folletos editada en Sevilla por el Grupo Risa y Alegría. El grupo, con sede en la calle Paloma 19 de la capital hispalense, patrocinaba un concurso literario-filosófico de sociología para autores noveles, con cuyos ganadores se editó un folleto que salió a la venta por 20 céntimos en 1903. El volumen incluía el poema El sueño de la esclava de Antonio Apolo, impresor anarquista extremeño que había publicado en Madrid La redención del campesino un año antes, y un pequeño ensayo del herrero sevillano y futuro falangista Joaquín Julio Fernández, El cristianismo y el tolstoismo. Antes de enero de 1904, apareció el que iba a convertirse en el segundo y último de sus títulos, una reedición de El dolor universal de Sebastián Fauré, que por ser muy extensa pretendía editarse en fascículos coleccionables al módico precio de 5 céntimos el ejemplar. Que sepamos solo salió el primero. Como administrador del grupo y de la colección figuraba un tal Manuel Rincón del que nada se sabe ${ }^{32}$.

Más prolongado fue el catálogo de Biblioteca Económica, editada en Sevilla desde 1903 por el grupo Gorki y administrada en la calle don Juan 11 por los militantes obreros Antonio Fresno y Francisco Rey, el cual era, al parecer, un conocido "paquetero" de la ciudad que fue detenido en numerosas ocasiones. Todos los folletos, independientemente de su extensión, salieron al precio de 5 céntimos. Aunque carecen de

31 Vid. Miguel Íñiguez, op. cit., II, pp. 1695-1696.

32 Para Joaquín Julio Fernández, vid. Íniguez, op. cit., I, pp. 587 y, para Apolo, ibidem, I, pp. 101-102. Con respecto a las actividades editoriales del grupo, Ignacio Soriano y Francisco Madrid, op. cit., pp. 85 y 171. 
numeración, es posible que el primero que editaran fuera De vuelta al terruño, firmado al alimón por Benjamín Merchán y el ya citado Joaquín Julio Fernández. Le habrían seguido una traducción de las Declaraciones del anarquista Etièvant, un diálogo pedagógico racionalista de José Sánchez Rosa titulado Las dos fuerzas (reacción y progreso), una reedición de Al Pueblo del anarquista catalán José Médico y Soto y otra de El evangelio del obrero de Nicolás Alonso Marselau. A este autor, con más propiedad que a otros, podría aplicársele el calificativo de "apóstol del proletariado", pues había sido, en efecto, seminarista en Granada antes de abrazar la causa obrera y convertirse, por el misticismo de su oratoria y su dominio del inglés, en representante de la Federación Regional Española en varios congresos de la I Internacional, mientras sucesivamente ejercía también como barbero, redactor de un periódico anglicano en Gibraltar, incendiario autor de "homilías laicas" en la cabecera sevillana La Razón, represaliado por delitos de prensa, prófugo internacional $y$, al final de sus días, de nuevo sacerdote católico en ejercicio y hasta defensor del carlismo. La primera edición de su exitoso El evangelio del obrero data de $1872^{33}$.

En 1904, y en todo caso antes de septiembre, iba a aparecer aún en Sevilla bajo el marchamo de Biblioteca Económica una reedición del título del popular anarquista italiano Pietro Gori, La anarquía ante los tribunales. Este, en cambio, se vendía ya a 15 céntimos y se distribuía desde la calle Industria, 4. Después de este título, la colección pareció truncarse.

Aunque existen dudas razonables acerca de que constituyan el mismo proyecto, lo cierto es que Biblioteca Económica va a reaparecer en Úbeda en 1906. Los volúmenes localizados seguían costando 5 céntimos, como al principio. Los pies de imprenta sitúan la administración en calle Altozano

33 Vid., para Marselau (1840-1882), Miguel Íniguez, op. cit., I, p. 61; José Luis Gutiérrez Molina "Nicolás Alonso Marselau". Dbe. Real Academia de Historia: http:// dbe.rah.es/biografias/13495/nicolas-alonso-marselau [consultado 24/02/2020] o Fran Andújar "El final de Nicolás Alonso Marselau". Ser Histórico. Portal de Historia, 2019: https://serhistorico.net/2019/06/08/el-final-de-nicolas-alonso-marselau/ [consultado 24/02/2020].

Sobre el catálogo (incompleto) de Biblioteca Económica, vid. Ignacio Soriano y Francisco Madrid, op. cit., p. 409. 
40 de la localidad jienense y como administrador figura un tal Manuel Gutiérrez. De ese año son tres folletos: una reedición de la obra de José Médico y Soto Al Pueblo, folleto inclemente contra el aborregamiento de las masas que ya había aparecido previamente en Biblioteca Económica en su primera etapa; una compilación de Canciones libertarias de diversos autores anónimos, a modo de himnos obreros, y la enésima reedición de Entre Campesinos de Errico Malatesta. En 1907 apareció La imprenta y la Iglesia, de F. Laurent, del que nada sabemos, como tampoco volvió a saberse nada de la colección a partir de esa fecha.

También sevillana fue la breve experiencia de Biblioteca El Despertar del Obrero, que editó solo un título en 1911, El capitalista y el Trabajador, acompañado de Los Inocentes, dos diálogos pedagógicos del maestro racionalista José Sánchez Rosa, un habitual, como estamos comprobando, de las colecciones anarquistas andaluzas.

La fundación en Córdoba en abril de 1913 de la Federación Nacional de Obreros Agricultores, que fue fundamental para vertebrar el anarquismo agrario, trajo también a la provincia a numerosos propagandistas ácratas, impulsores de diversos proyectos culturales. Es el caso de Manuel Pérez y Pérez, agricultor de Écija, y de la sindicalista sevillana y congresista de la FNOA, habitual de la prensa obrera, Ángeles Montesinos. Trasladados a la zona para la ocasión, fundaron Centros Culturales Obreros en Bujalance, Cañete, Castro del Río o Fernán Núñez, antes de recalar en La Carlota, donde impulsaron un Centro Instructivo de Oficios y Profesiones Varias y una importante Casa Escuela. Para financiarla crearon en 1913 la Asociación Protectora de Enseñanza Racionalista que, además de diversas actividades culturales en el municipio, editó la colección de folletos "proracionalismo". Únicamente aparecieron dos números, al precio de 10 céntimos: el primero fue La peste religiosa de Johan Most, un clásico del ateísmo conocido en nuestro país desde 1903, cuando fue editado por Juventud Libertaria de Barcelona.

El segundo, una selección de textos, preparada por los editores, de otra gran figura del anarquismo internacional, C. Malato: Historia del Primer anarquista; fundamentos de la idea anarquista; Los que producen. Por los datos que aporta Íniguez, tras el cierre de la Escuela, Montesinos regresó a Sevilla, donde parece que se acabó pasando al comunismo. Por su parte, Manuel Pérez y Pérez trabajó en un taller de fotografía y continuó como 
activista en comarcas agrícolas de la zona como Fuente Palmera, Espejo, Puente Genil o Castro del Río, donde se retiró en $1921^{34}$.

También en 1913 y en Córdoba existió Biblioteca Recreativa de Propaganda Sociológica, localizada en la calle San Basilio, 16. Su impulsora, administradora y autora única fue la planchadora y activista obrera Rafaela Salazar López, que había llegado desde Écija a la vieja capital del califato con Manuel Manzano del Real, célebre sindicalista campesino y secretario en el congreso que dio lugar a la FNOA. En realidad, si hemos de creer a Díaz del Moral, gran parte de la popularidad de Manzano se la debe a ella, que le escribía los discursos, y hasta algunos de los folletos que se le atribuyen. En todo caso, en la colección que aquí referenciamos llegaron a salir tres atrevidos ensayos de Salazar: En las catequistas, La mujer y el cura y Sólo para mujeres, los tres de 1913, y quedaron anunciados en prensa sus obras teatrales Redención y Palmira; esta última tal vez se trate del polémico drama atribuido a Manzano cuya representación fue prohibida por la autoridad en Écija en $1906^{35}$.

Eminentemente rural fue el proyecto "Ya Despertamos" promovido por una sociedad de agricultores de Dos Hermanas que, además de un centro cultural obrero y una escuela para trabajadores, intentó editar una colección de folletos para financiarla. Conocemos, por referencias de prensa, un único título de 1914 a 20 céntimos, Los impios, de Antonio Muñoz Benítez, jornalero de Arcos de La Frontera, alumno de José Sánchez Rosa y luego maestro racionalista conocido por el sobrenombre de "El laico". Es posible que fuera el director de la escuela para obreros de Dos Hermanas, municipio del que llegó a ser concejal de instrucción pública con el Frente Popular. Fue fusilado por el fascio en 1936 sin conocérsele más obra que la mencionada ${ }^{36}$.

34 Para Montesinos vid. Miguel Íniguez, op. cit., II, p. 1149. Para Manuel Pérez y Pérez, vid. Miguel Íniguez, ibidem, II, p. 1333. De su experiencia propagandista en Córdoba, Juan Díaz del Moral, op. cit., pp. 243 y 255. En cuanto a la Asociación Protectora de Enseńanza Racionalista, Ignacio Soriano y Francisco Madrid, op. cit., pp. 214 y 279.

35 Vid. Ignacio Soriano y Francisco Madrid, op. cit., pp. 346 y 256; Miguel Íniguez, op. cit., II, p. 1544; y Juan Díaz del Moral, op. cit., p. 255.

36 Vid. Miguel Íníguez, op. cit., II, p. 1183, y Ana María Montero-Pedrera, "Muñoz Benítez epígono de la escuela racionalista”, Andalucía en la Historia, 19 (2008), pp. 10-13. 
Asimismo, con el objetivo de financiar una escuela para trabajadores, apareció en 1915 en Jerez de la Frontera la Biblioteca de Cultura Obrera impulsada por el viticultor Sebastián Oliva Jiménez, destacadísimo militante agrario en la Baja Andalucía y secretario general de la FNOA. Oliva tenía experiencia como gestor cultural, pues ya dirigía, desde 1914, La voz del campesino, el más importante vocero ácrata de la provincia de Cádiz, y su activismo como asesor de la CNT en temas agrarios no decayó hasta 1936, año en el que las razzias de Queipo de Llano acabaron con su vida en Sevilla. De Biblioteca de Cultura Obrera salieron tres títulos, con un formato de 19x13 y un precio de entre 20 y 25 céntimos: los dos primeros fueron obras del gran teórico libertario gallego Ricardo Mella, Las grandes obras de la civilización y El ideal anarquista. La ascensión de la Ciencia de Emilè Hureau figuraba como número tres. Nueva Humanidad, del militante zaragozano José Chueca, cerró la colección en 1920. Como imprenta figuraba el establecimiento tipográfico de M. Martín. Probablemente para esquivar las zancadillas de la autoridad, figura como administrador de la colección Juan Cordero, al parecer maestro en la cercana localidad de Lebrija. Cordero aparece también como receptor de los pedidos de otra efímera colección de folletos, la Biblioteca Luz de Lebrija que, bajo el sello de la Asociación de Obreros Campesinos, publicó en 1916 un único folleto, La Imprenta y la Iglesia de F. Laurent, ya editado previamente por la Biblioteca Económica de Úbeda ${ }^{37}$.

La aislada localidad malagueńa de Montejaque, en la serranía de Ronda, fue en 1917 la sede inicial de Los Nuestros, proyecto editorial impulsado por el egabrense Salvador Cordón, importante propagandista ácrata y fundador de la escuela obrera del municipio. Cordón, después de un exilio en Argentina de casi diez años, había iniciado en 1913, junto con su compañera Isabel Hortensia Pereira, una importante labor pedagógica y cultural en Andalucía, fundando centros educativos para obreros en Castro del Río, Montejaque, Aznalcóllar o Algeciras, y revistas como Alas o Prometeo. Según Díaz del Moral, que lo escuchó en Montilla, su oratoria en los mítines no generaba tanto efecto como la de su compañera, con la que fundó también el Centro Obrero de Navás, en Cataluña, antes de regresar a Argentina, donde al parecer murió

37 Vid. Miguel Íńiguez, op. cit., II, p. 1227, y Jacques Maurice, op. cit., pp. 270-274. Hay datos de la colección en Ignacio Soriano y Francisco Madrid, op. cit., p. 404. 
en un accidente de tráfico en los años cincuenta. Con ella co-escribió también la obra teatral La virgen roja, dedicada a la comunera Louise Michel, e incluso algunas zarzuelas de corte militante como Carmeliya, la montiyana. Salvador Cordón es autor, asimismo, de numerosas novelas breves, entre las que destaca Pueblo en sombra, así como de un interesante libro de memorias, De mi bohemia revolucionaria, aparecido en 1921. La experiencia de Los Nuestros, que conocemos solo por referencias, fue singular, pues, a diferencia de lo que era común en la edición libertaria, apostó por obras de ficción en su única serie: La novela libertaria, "novelarelámpago de crítica e ideas", que puso en la calle solamente tres números a 5 céntimos, con periodicidad quincenal y formato probablemente de revista. El primero incluía ya dos títulos, La locura de Mari de S. Donkor, seudónimo bajo el que se ocultaba el propio Salvador Cordón, y A Violín del maestro racionalista vallisoletano Luis Zoais, que también aparecía en el siguiente ejemplar de La novela libertaria con su texto Vida, compartido esta vez con el militante alicantino José Pagán Navarro, quien abría el volumen con ¡Paria! El panadero y activista madrileño Mauro Bajatierra firmaba en exclusiva el tercero con Asomándose a la vida, que se presentó como "extra" a 10 céntimos. Todavía ese mismo año germinal de 1917 aparecería en Aznalcóllar, aunque ya sin referencias a la serie, La mina, del propio Salvador Cordón ${ }^{38}$.

El predio latifundista jienense de Linares, cuna de varios periódicos obreros, fue el escenario de las andanzas del grupo de afinidad ácrata Luz y Vida, impulsor de la Biblioteca Luz y Vida, que llegó a alcanzar los diez títulos entre 1919 y 1921. Con sede en la calle Tinte, 47, el grupo consignaba a una tal Dolores Herrera como receptora de los pedidos, pero el verdadero impulsor de la colección de folletos fue el activo militante madrileño, entonces de gira por Andalucía, Diego Alonso, quien inauguró también la colección con El naufragio de una creencia.

Hacia el número 7, probablemente en torno al verano de 1920, la Biblioteca Luz y Vida se traslada a Torredelcampo, también en Jaén. Con un precio de entre 15 y 20 céntimos por ejemplar, los folletos estaban

38 Existe una biografía de Salvador Cordón: Alberto Gay, "Salvador Cordón Avellán. Militante y escritor libertario". El paseo cultural, 1 (1997), pp. 35-59. Vid. también Juan Díaz del Moral, op. cit., pp. 256-257 y 271; y Miguel Íniguez, op. cit., I, pp. 445-446; y, para Pereira, ibidem, II, p. 1313. 
numerados y presentaban obras inéditas de jóvenes militantes, algunos de ellos andaluces, como el cordobés Salvador Cordón, que firmó el número dos, La siega que viene, o el onubense Higinio Noja, un muy eficaz narrador, que es el autor mejor representado de la serie, pues firma dos títulos: el tercero, Tragedias Vulgares, y el quinto, Amapolas y Ortigas. El número cuatro, Flores Rojas, y el sexto, Argumentos revolucionarios, son antologías, la primera de versos y la segunda de prosas, de diversos y desconocidos autores vinculados al mundo obrero. El séptimo título, Gracia de indulto de José Pagán Navarro, aparece ya en Torredelcampo, al igual que el octavo, El terror en Valencia. Proceso de la "Unión Española" del propio Diego Alonso.

Este último parece cerrar precipitadamente la serie, pues los dos títulos restantes de la Biblioteca no sabemos si llegaron a editarse. En todo caso aparecen referenciados en prensa como de próxima aparición Caramañola, de un tal Arnaldo Danel y ;Madre! de la importante pedagoga, naturista y militante ácrata, muy activa en la zona levantina, Antonia Maymón ${ }^{39}$.

Uno de los más atractivos proyectos editoriales ácratas en Andalucía fue, sin duda, Renovación Proletaria, en la aldea minera del alto Guadiato cordobés Pueblonuevo del Terrible. En las precarias condiciones de la Andalucía rural de entonces, la editorial llegó a poner en la calle veintitrés títulos y a alcanzar, en sus apenas cuatro años de existencia, los 449.000 ejemplares vendidos, además de distribuir en el extranjero. Como en la mayoría de estas empresas culturales, detrás del proyecto se encontraba el maestro racionalista de la localidad, en este caso Aquilino Medina, activista libertario con escuela obrera en calle San Pedro, 27, donde se domicilió también la editorial. Aunque desconocemos si era natural de Pueblonuevo, lo cierto es que siempre estuvo muy vinculado al municipio, donde fundó también el semanario obrero Nuevo Rumbo y donde, además, regentaba una imprenta.

Con la idea de divulgar obra inédita de jóvenes autores españoles, Medina emprendió en diciembre de 1919 la publicación de Biblioteca

39 Vid. para Diego Alonso, Juan Díaz del Moral, op. cit., pp. 253-254, Miguel Íńiguez, op. cit., I, p. 58, y Francisco Moreno Gómez, "El obrerismo andaluz en el primer tercio del S.XX (2)", Historia, Memoria y Literatura, 2019: http://www.franciscomorenogomez.com/2018/01/la-larga-marcha-del-obrerismo.html. [consultado 24/02/2020]. Para la Biblioteca, Ignacio Soriano y Francisco Madrid, op. cit., p. 438. 
de Renovación Proletaria, una serie de "volúmenes filosóficos" de amplio formato (20x14) con innovadores juegos tipográficos y fotografías de los autores en portada, 24 páginas cada uno y 25 céntimos por ejemplar. La colección, que pretendió, sin conseguirlo, ser mensual, combinaba ensayos, reportaje y novelas sociales de prometedoras pero aún desconocidas plumas de la nueva "intelectualidad" proletaria, de manera que autores como Ángel Pestaña y Salvador Seguí (El sindicalismo en Cataluña), Manuel Buenacasa (La Rusia Roja), Galo Díez (La mujer en la lucha social), Ángel Samblancat (Bocanadas de fuego y La violencia), David Díaz (La Bancarrota del socialismo), Valentín de Pedro (El sindicalismo frente a la política), Higinio Noja (Brazo y cerebro y La palanca de Arquimedes) o el propio Aquilino Medina (Más allá de la política) debutaron en la joven editorial.

Probablemente el precinto de la imprenta precipitó, en octubre de 1922, la marcha de Medina a Herrera, en la sierra sur hispalense, donde en calle Alpechín,17 montó de nuevo escuela y reanudó las actividades de Renovación Proletaria, utilizando ya diversas imprentas para regatear la censura. Alumbró allí los últimos seis títulos de su colección de "volúmenes filosóficos" hasta cerrar la serie con veintiuno en mayo de 1924. También en Herrera, bajo el marchamo de Renovación Proletaria, aparecieron ¿Qué es la anarquía? de Kropotkin y Los galeotes del amor de Higinio Noja, que tal vez aspiraban a iniciar nuevas colecciones, una de clásicos de la acracia a 5 céntimos, y otra de novelas más largas y precio elevado (2,50 la primera).

En todo caso, se frustraron con la represión del régimen de Primo de Rivera, que clausuró la editorial y desterró al activista a Cuenca, donde al parecer regentó una librería-distribuidora. No obstante, Medina parece estar también detrás de los dos títulos publicados por editorial Renovación, el primero, Comunismo de Higinio Noja, en 1924, todavía en Herrera, y el segundo, ya en Puente Genil, de nuevo en Córdoba, La mujer de Antonio Verdú, en 1925. Desde su nueva ubicación en la campiña cordobesa, Medina dirigió también Editorial Pedagógica, ubicada en la calle don Gonzalo, 6 del mismo Puente Genil, y en ella publicó dos importantes colecciones de folletos de impecable factura, ilustrados, exclusivamente de ficción y de autores por lo general consagrados, algo infrecuente en las colecciones libertarias: la primera, La Novela Decenal, consiguió sacar once números (32 páginas de 17x12 a 15 céntimos ejemplar), numerados 
y fechados de abril a noviembre de 1926, incorporando títulos de narradores libertarios vinculados personalmente a Medina, como Higinio Noja (El Gracián que asesinó y Polvo y humo) o Ángel Samblancat (La bestia de la dulce sonrisa), junto con autores ya más bien novecentistas como Manuel Ciges (La aventura del profesor Maroto) y Ramón Pérez de Ayala (El ejemplo de Rosendo Toral), o incluso populares bohemios como Pedro de Répide (Afán de vivir) o Eugenio Nöel, que cerró la serie con La novela de un pueblo en capea.

La segunda colección de Editorial Pedagógica es La novela Corta, que compartía nombre con el célebre proyecto semanal madrileño de José Urquía que llegó a alcanzar quinientos títulos entre 1916 y 1925. La de Puente Genil solo consiguió editar cuatro en 1928: Cara y Cruz del militante ácrata argentino Alberto Ghiraldo; La rebelión de Lulilo de Federico Torres; La libérrima del propio Medina y Chantajismo amoroso del periodista asturiano Edmundo González Blanco, que cerró la colección ${ }^{40}$.

Con todo, la más importante editorial libertaria surgida en Andalucía, y una de las más longevas de España, fue la impulsada en Sevilla por el maestro racionalista José Sánchez Rosa. Se trata de Biblioteca del Obrero, que funcionó desde 1913 a 1936, primero en calle Enladrillada, 49, en el Barrio de San Julián, y después en Peris Mencheta, 33, en la Alameda de Hércules, otra zona deprimida de la ciudad. La editorial era, como en tantos casos, proyecto complementario a la Escuela Racionalista para hijos de obreros por las mańanas y para los propios trabajadores por las noches, que dirigía Sánchez Rosa junto a su pareja, la maestra titulada Ana Villalobos. Utilizó como imprenta principal la de los hermanos Madolell y, en los años treinta, la tipográfica Casa de la Vega.

Es significativo que Sánchez Rosa, uno de los más importantes pedagogos racionalistas de su tiempo, reconocido en todo el mundo,

40 Como de tantos "apóstoles de la cultura", de Aquilino Medina no se conocen siquiera las fechas de su existencia. Que sepamos, su última aparición fue en el semanario de Herrera Alma Agraria, en noviembre de 1931 (agradezco sobremanera al historiador Juan Jesús Álvarez Luna que me llamara la atención sobre el dato y me hiciera llegar el ejemplar donde aparece). Para Medina, vid. Miguel Íniguez, op. cit., p. 1099, Juan Díaz del Moral, op. cit., p. 270, y Jacques Maurice, op. cit., p. 284. Sobre la editorial terriblense, vid. el monográfico Alejandro Civantos Urrutia, "Más allá de la política: 'Renovación Proletaria', una editorial anarquista desde la entraña de Andalucía”, Sociocriticism, XXXII, 1 (2017), pp. 45-80. 
no tuviera en realidad título oficial y ni siquiera hubiera cursado el bachillerato. En Grazalema, donde había nacido en 1864, ejerció de ayudante en el taller de remiendo de zapatos de su padre y, sobre todo, fue jornalero desde los catorce años, lo que le permitió conocer la realidad del latifundio, cuyas condiciones empezó a denunciar tempranamente. Condenado a cadena perpetua tras el alzamiento de Jerez en 1892, en la cárcel mejoró sus conocimientos, aprendió idiomas y, sobre todo, conoció a Fermín Salvochea, quien fue el verdadero impulsor de su cultura societaria. Indultado en 1901 con motivo del enlace de la princesa de Asturias, la formación de los más desfavorecidos fue ya la prioridad de su vida; así, estaba decidido a combatir la indigencia intelectual y la educación milagrera que, a su juicio, se infligía al proletariado en las escuelas oficiales.

Trabajó inicialmente como maestro en un Centro de Estudios Sociales de Los Barrios, pero enseguida empezó a fundar escuelas para obreros en otras localidades deprimidas como Algeciras, La Línea, el Campo de Gibraltar, Tánger o Aznalcóllar, labor que iba complementando con la edición de folletos educativos, primero por cuenta propia y, a partir de 1913, en Biblioteca del Obrero. Su importancia como docente fue tal que en 1910 llegó a dirigir la Agrupación de Enseñanza Racionalista de España. En cambio, su posición dentro de la CNT nunca llegó a ser tan sólida, pues era firme partidario de la creación de una Regional Andaluza Independiente, lo que provocó su expulsión del sindicato en 1919 en medio de un escándalo mayúsculo por tratarse del "decano de los agitadores anarquistas peninsulares”, en palabras de Díaz del Moral. Durante la dictadura de Primo de Rivera, fue deportado a África durante algunos meses y encarcelado en Murcia por un periodo de dos años. Además, su escuela de Sevilla fue perseguida con saña. El 18 de Julio de 1936, la primera de las razzias de los requetés en Sevilla fue a detenerlo a su escuela del Barrio de San Julián, donde aún trabajaba, infatigable, con Ana Villalobos y la mayor de sus hijas, Paca. Fue fusilado el 31 de Julio en las inmediaciones del Cementerio de Sevilla ${ }^{41}$.

41 Además de la excelente monografía de la que disponemos (José Gutiérrez Molina, La tiza, la tinta y la palabra. José Sánchez Rosa, maestro y anarquista andaluz (18641936), Cádiz, Tréveris, 2005), vid. Juan Díaz del Moral, op. cit., pp. 249-252, Jacques Maurice, op. cit., pp. 170-181, y Miguel Íniguez, 2008, op. cit., pp. 1570-1571. 
En sus más de veinte años de actividad, la Biblioteca del Obrero publicó algunos títulos indispensables en su esfuerzo por crear una cultura de clase que permitiera al proletario comprender el mundo para poderlo transformar. El primero, y quizá el más famoso, fue El Abogado del Obrero, que Sánchez Rosa había publicado por cuenta propia en 1912 agotando la edición en un mes. Biblioteca del Obrero presentó el volumen al año siguiente con prólogo de Eduardo Barriobero a 1,50 pesetas y 288 páginas en un tomo encuadernado. Lleno de formularios para reclamaciones, derechos de indemnización y ajustadas síntesis para leer mejor la letra pequeña de los contratos, el libro, subtitulado "recopilación de leyes referentes a la clase obrera", con sucesivas ampliaciones y adaptaciones a la legislación vigente en cada momento, llegó a alcanzar, a pesar de su precio, trece ediciones hasta 1933, fecha en que está documentada la última de la que tenemos noticia.

La obra, cuyo éxito daba la medida de las necesidades del lector proletario, venía a continuar una trilogía de divulgación básica para trabajadores que Sánchez Rosa había empezado en Aznalcóllar en 1909 con La Aritmética del Obrero (150 páginas a 0,75 céntimos), que la editorial sevillana consiguió llevar hasta las dieciséis ediciones en 1935, y culminaba con La Gramática del Obrero (179 páginas a 2 pesetas), que apareció en 1929 y llegó a documentar cuatro, proponiendo "más de 300 demostraciones prácticas con las que, muy fácilmente, se aprenderá a pronunciar las letras y, en una palabra: a escribir con ortografía”.

No obstante, estos eran títulos de lujo en un catálogo principalmente de folletos rústicos de $17 \times 12,16$ a 24 páginas y entre 10 y 20 céntimos de precio, compuestos ad hoc por el propio Sánchez Rosa para ilustrar a sus alumnos, como la novela social Bienvenida (1914), el cuentecillo pedagógico Entre amiguitas: Azucena, Dalia y Camelia (1912) o el diálogo El burgués y el anarquista (1914). O bien de reediciones de otros títulos del autor utilizados en anteriores experiencias educativas: El obrero sindicalista y su patrono (1911; dos ediciones); Los dos profesores (1911; reeditado en 1931); Los dos niños de la Escuela, complementario al anterior (1911; también reeditado en 1931); El capitalista y el trabajador (1905; con cinco ediciones más en Biblioteca del Obrero); En el campo: el guarda y el obrero (1911; cinco ediciones), La idea anarquista, que El Despertar del Terruño había publicado en 1903 y del que Biblioteca del 
Obrero hizo dos ediciones más, o Las Dos Fuerzas (reacción y progreso), que Biblioteca del Obrero reeditaba en 1931 después de cinco apariciones en otras editoras libertarias.

Si bien Sánchez Rosa fue el principal proveedor de títulos de Biblioteca del Obrero, esta editó también a otros autores. Clásicos del anarquismo internacional, traducidos a menudo por el propio editor, junto con propagandistas sociales, divulgadores del feminismo o el pacifismo fueron desfilando por la editorial y proponiendo, a precio económico, un conjunto de temáticas realmente infrecuentes en nuestro país: Pedro Gori con La anarquía en los tribunales; Sebastián Faurè con El dolor Universal; Jean Grave con El sindicalismo en la evolución social; Marius Jacob con ¿Por qué he robado?; André Lorulot con títulos como El idolo Patria o El problema de los sexos; las célebres Declaraciones de Etièvant; Magdalena Vernet con El amor libre; Albert Libertad con El culto a los muertos; Anselmo Lorenzo con Fundamento y principales tendencias del anarquismo contemporáneo; Ricardo Mella con Organización, agitación y Revolución; o José López Montenegro, divulgador científico del que se editaron el poema de historia natural La Naturaleza en 1913 y en 1916 unas Nociones de Sociología, además de su preciosa enciclopedia de "orientación sociológica" El Botón de Fuego (1934), que incluía unas "Nociones de Geología y Sociología para la enseñanza de los trabajadores". Biblioteca del Obrero editó también a algunos otros propagandistas y escritores libertarios más desconocidos como Vicente March con ;Cómo nos diezman!; Ángel Villave con Un grano de arena o Luis Zoais con Anarquismo triunfador, y hasta un Cancionero revolucionario y la enésima reedición del legendario poema anticlerical ¿Dónde está Dios? de Miguel Rey.

La editorial sevillana difundió también obras de numerosos autores andaluces, intelectuales de los márgenes como el maestro racionalista cordobés Clodoaldo Gracia, del que se editó De mi breviario; el exseminarista granadino Nicolás Alonso Marselau con su muy popular El evangelio del obrero; el egabrense Salvador Cordón, del que Sánchez Rosa editó Frente al Estado; Dionysos, seudónimo del propagandista granadino Antonio García Birlán, que llegó a ser consejero de Sanidad de la Generalitat durante la Guerra Civil, y del que apareció ;A la lucha!; o del minero onubense Higinio Noja Ruiz, pedagogo racionalista en el Cabañal y editor de la importante revista-editorial valenciana Estudios, 
del que Biblioteca del Obrero editó Mi único amor en 1914. En definitiva, un repertorio de desconocidos y entusiastas aspirantes a construir una alternativa cultural que la Guerra Civil frustró para siempre.

\section{Conclusiones}

En el contexto de las primeras décadas del s.XX, las colecciones anarquistas, por lo general poco investigadas, ocuparon un lugar vacante en el mercado editorial andaluz. Con la manifiesta intención de combatir la incultura en la que se hallaba el proletariado y de hacerlo, además, con medios propios, las publicaciones ácratas establecieron un fructífero diálogo con las colecciones de novela breve de su tiempo y realizaron, asimismo, algunas aportaciones originales, reclamando otros niveles de comunicación de fuerte base colectiva y un criterio militante de la acción cultural. Impulsados desde asociaciones profesionales, colectivos sindicales o escuelas obreras, la mayor parte de estos proyectos surgieron en pequeños municipios agrícolas o mineros, localidades aisladas o zonas latifundistas de la baja Andalucía absolutamente carentes de industria editorial.

La singularidad de sus métodos de distribución, la novedad de algunas de sus temáticas y el hecho fundamental de que los autores procedieran del mundo del trabajo manual propiciaron que numerosos lectores obreros, recién salidos del analfabetismo, se identificaran con este tipo de productos culturales económicos, de modesta factura y que rechazaban la aristocracia espiritual del libro en favor de modelos más urgentes y combativos de comunicación social. Aunque resulta difícil cuantificar su éxito, estas propuestas editoriales consiguieron configurar un espacio cultural que contribuyó de manera notable al arraigo del anarquismo en Andalucía y a diseñar, durante casi cincuenta años, las esperanzas del proletariado como clase social. 